\title{
Aquaporin-4 Isoform Expression in the Developing Mouse Nigro-striatal System
}

\author{
Eva Küppers • Veronica Brito • Britta Wachter • \\ Hartwig Wolburg • Cordian Beyer
}

Received: 22 July 2008 / Accepted: 27 August 2008 /Published online: 9 September 2008

(C) Humana Press 2008

This paper has been retracted at the request of the authors because consent to publish was not given.

This paper has been retracted at the request of the authors because consent to publish was not given.

E. Küppers $\cdot$ V. Brito $\cdot$ B. Wachter Institute of Anatomy, University of Tübingen, 72076 Tübingen, Germany

H. Wolburg Institute of Pathology, University of Tübingen, 72076 Tübingen, Germany

C. Beyer

Institute of Neuroanatomy, Medical Clinic, RWTH Aachen University,

52057 Aachen, Germany

C. Beyer $(\square)$

Institut für Neuroanatomie, RWTH Aachen University,

Wendlingweg 2,

52074 Aachen, Germany

e-mail: cbeyer@ukaachen.de 